\title{
Cross-Border Health and Productivity Effects of Alcohol Policies
}

\author{
Per Johansson, Tuomas Pekkarinen†, Jouko Verho ${ }^{\ddagger}$
}

8th November 2011

\begin{abstract}
This paper studies the cross-border health and productivity effects of alcohol taxes. We estimate the effect of a large cut in the Finnish alcohol tax on mortality, alcohol related illnesses and work absenteeism in Sweden. This tax cut led to large differences in the prices of alcoholic beverages between these two countries and to a considerable increase in cross-border shopping. The effect is identified using differences-indifferences strategy where changes in these outcomes in regions near the Finnish border are compared to changes in other parts of northern Sweden. We use register data where micro level data on deaths, hospitalisations and absenteeism is merged to population-wide micro data on demographics and labour market outcomes. Our results on the effect of the Finnish tax cut on mortality alcohol-related hospitalisations in Sweden are very imprecise. However, we find that workplace absenteeism increased by $5 \%$ for males and by $13 \%$ for females near the Finnish border as a result of the tax cut.
\end{abstract}

\section{Introduction}

Excise taxes on alcohol are a widely used tool of alcohol policy. Indeed, most developed countries impose some taxes on alcohol. In the United States alcohol is taxed at the federal, state, and, sometimes even at the

${ }^{*}$ IFAU and Department of Economics, Uppsala University and IZA.

${ }^{\dagger}$ Aalto University School of Economics and IZA.

${ }^{\ddagger}$ Research Department, The Social Insurance Institution of Finland and IZA.

The Centre for Social research on Alcohol and Drugs (SORAD) is acknowledged for providing data on alcohol consumption and sales in Sweden and Alko is acknowledged for providing alcohol sales data in Finland. We are grateful for the financial support from the Finnish Foundation for Alcohol Studies. 
local level. In Europe, the member states of the European Union have agreed on a minimum alcohol tax rate but left it to individual member states to determine the final rate of alcohol taxation. Consequently, there is considerable variation in the rate at which alcohol is taxed within the EU with the Nordic countries typically imposing the highest taxes and wineproducing countries of Southern Europe applying the lowest rates.

While the revenue from alcohol taxes is non-trivial, perhaps the main motivation for taxing alcohol is to reduce the consumption of alcohol. Excise taxes on alcohol have been seen as a way of internalising the external costs of alcohol use. Ideally, according to the Pigouvian principle, the tax on alcohol should equal the expected monetary value of the external costs of alcohol consumption. However, the scope for national excise taxes to affect alcohol consumption is limited by the possibility of making purchases from bordering jurisdictions with lower tax rates. In the European Union this is a relatively new problem that has affected the old member states from the creation of the single market in 1994 and some members from as late as 2004 when the transitional restrictions for most recent members were removed. According to Cnossen (2007), some 12 percent of the EU population lives near a border with another member state. The scope for tax avoidance is therefore considerable.

The possibility of cross-border shopping has obvious implications for tax revenues and this has led many high tax countries to re-consider their alcohol taxes. It has been argued that in order to avoid the loss of revenues due to cross-border shopping, excise taxes on alcohol should be cut closer to the levels in neighbouring countries. However, to fully understand the implications of cross-border shopping for the efficiency of excise taxes, one would need to know the externalities caused by cross-border shopping. This cannot be inferred directly from revenue losses, since the responsiveness of the demand for alcohol with respect to foreign prices is likely to be substantially heterogeneous. If the harmful externalities caused by cross-border shopping are minor, there may still be scope to maintain high excise taxes on alcohol despite the revenue losses due to cross-border shopping.

In this paper, we examine cross-border health and productivity effects of national excise taxes on alcohol. More specifically, we study the effects of a reduction in the Finnish alcohol tax on mortality, alcohol-related hospitalisations, and sickness absence in the Swedish regions that are close to the Finnish border. We use inpatient register data that cover all hospitalisations in Sweden. Furthermore these data are linked to a population database that includes information on income and employment as well as basic demographics on the whole Swedish population. We identify the effects of the 
Finnish tax cut by contrasting the changes in the outcomes near the Finnish border to changes in outcomes in the regions that are further away from the border.

On March 1st, 2004 Finland implemented a large tax cut that lead to an average 19 percent decrease in the retail prices of alcoholic beverages. For beverages with high alcohol content, such as spirits, the reduction in price was even larger with an average cut of 36 percent (Lankinen 2005). We focus on the health and productivity effects of this tax cut in the Swedish regions that are adjacent to the Finnish border.

We believe that the Finnish and Swedish border regions provide an exceptionally promising setting for analysing the cross-border health and productivity effects of national alcohol policies. First of all, Finland and Sweden have traditionally pursued very similar alcohol policies with high excise taxes and very strict regulation of the sale of alcohol. In both countries, the retail sale of alcohol is restricted to government monopoly outlets, Systembolaget in Sweden and Alko in Finland that set homogeneous prices within the country. These common features of the Finnish and Swedish alcohol policies make it easy to estimate the effect of alcohol taxes since they imply that the prices or the supply of alcohol do not vary endogenously within countries. At the same time, exchange rate variation and major tax changes, such as the Finnish tax cut studied here, mean that there is considerable variation in prices between Finland and Sweden over time. Second, Finland and Sweden are both member states of the European Union. Until January 1st, 2004 both countries imposed transitional restrictions on how much alcohol for personal use could be brought in from other member states. However, in January 2004 these restrictions were lifted and the ways in which these countries reacted to this change were very different. Whereas Finland significantly reduced taxes on alcohol in March 2004 as a reaction to having to allow unlimited import of alcohol for personal use from Estonia, which is easily accessible from southern parts of Finland, Sweden left alcohol taxes unaltered. Hence, the Finnish tax cut led to large price differences for identical products between Finland and Sweden in a setting where there were no legal restrictions on cross-border shopping for personal consumption.

The results on how these changes in relative prices affected health and productivity in a country that did not implement any policy changes are important for the understanding of cross-border effects of excise taxes within European Union in general. Moreover, focusing on cross-border shopping offers a novel way of evaluating the health and productivity effects of alcohol policies since regions near and far from the border can be used as treatment and control groups respectively. In our opinion this approach yields more 
credible estimates of the effect of alcohol policies since one is no longer restricted to before-after comparisons that have to be used when studying the effects on nationwide policies within jurisdictions.

The rest of the paper is structured as follows. In the following section, we survey the previous literature and argue that this paper addresses an issue which has not been properly studied in the existing literature. The third section presents the data sets used in the analysis. In the fourth section, we show that the Finnish tax reduction led to substantial declines in alcohol sales in the Swedish outlets near the Finnish border but not in the regions further away from the border. The fifth section presents the health and productivity effects of the Finnish tax cut in Sweden. Our estimates of the effect of the Finnish tax cut on mortality and alcohol-related hospitalisations are very imprecise. However, we find significant effects on absenteeism. Finnish alcohol tax cut lead to increased workplace absenteeism in the Swedish regions near the Finnish border by $5 \%$ for males and by $13 \%$ for females when compared to those over $100 \mathrm{~km}$ away from the border. The sixth section concludes.

\section{Previous literature}

There is an extensive literature estimating the price elasticity of demand for alcohol. A recent meta-study by Wagenaar et al. (2009), surveying over 100 studies on this issue, found that the average estimates of elasticities varied from -0.46 for beer to -0.80 for spirits. Yet there is also evidence that these average elasticities mask considerable heterogeneity in the responsiveness of demand. According to an influential study by Manning et al. (1995), the consumption of the median drinker is twice as elastic as that of the heavy drinkers. A recent study by Ayyagari et al. (2009) provides evidence that certain groups of heavy consumers are not responsive to prices at all.

Since the health effects of alcohol consumption are overwhelmingly related to large scale consumption which appears to be less responsive to price, it is not entirely straightforward to draw conclusions on the health effects of alcohol policies from aggregate price elasticities. A potentially more fruitful, reduced form approach is to study the health effects of alcohol policies directly. The amount of papers that attempt to do this is much more limited and they provide somewhat mixed evidence. Many of these studies use state-level data from the United States. Studies that examine the effect of state excise taxes on the cirrhosis mortality come up with mixed evidence (Grossman 1993, Sloan et al. 1994). There is stronger evidence on the ef- 
fects of state taxes on workplace injuries (Ohsfeldt \& Morrisey 1997) and on sexually transmitted diseases (Chesson et al. 2000).

The difficulty with the studies using aggregate state-level data is that it is hard to disentangle the effect of state taxes from state-specific shocks. Using abrupt policy changes and micro data is potentially a more promising way of assessing the health effects of alcohol policies. In this paper, we focus on the Finnish alcohol tax cut of 2004 which was precisely the kind of abrupt policy change that should allow for clean identification. The health effects of this policy change in Finland have been studied by Herttua et al. (2008). In what is essentially a before and after comparison of mortality rates, the authors find that alcohol-related mortality increased sharply (16\% for men and $31 \%$ for women) after March 2004, when the Finnish alcohol tax rates were cut. The results in Herttua et al. provide support for the externality reducing effects of national excise taxes. However, due to the fact that the identification is essentially limited to time-series variation, it is possible that the results reported in Herttua et al. confound the effects of the tax cut with other changes that took places in Finland at the same time. ${ }^{1}$

So far, the literature on cross-border shopping has been limited to studies that attempt to quantify the amount of cross-border shopping in different contexts. These studies typically find cross-border shopping to be substantial in settings where price differences are large and geographic distances small. For instance, according to Merriman (2010) in the city of Chicago where the dollar amount total taxes on a pack of cigarettes is nearly four times as large as in some of the neighbouring counties in Illinois, a $\$ 2.65$ difference in prices reduces the probability of finding a littered packet of cigarettes with the local Chicago stamp by $60 \%$. This is likely to be an extreme example, but even in cases where individuals have to cross national borders, the extent of cross-country shopping may be substantial. In a study that is closely linked to our paper, Asplund et al. (2007) estimate the elasticity of sales in the Swedish government alcohol retail monopoly with respect to Danish alcohol prices. This elasticity is around 0.3 in the border region and decreases to 0.2 when moving $150 \mathrm{~km}$ inland. According to the calculations by Asplund et al. these elasticities may result in substantial revenue losses for the Swedish government.

But the revenue impact does not capture the full implications of crossborder shopping on the social welfare effect of excise taxes. As shown by

\footnotetext{
${ }^{1}$ For example, Estonia joined the European Union in January 2004 allowing unlimited imports of alcohol for personal use. The only study trying to disentangle the effects of the tax cut and Estonia joining the EU is Koski et al. (2007) which also is limited to analysing time-series variation.
} 
DeCicca et al. (2010), this requires the estimation of the negative externalities that are generated by cross-border shopping. Again, as in the case of the effects of alcohol policies within national borders, it is not straightforward to infer these externalities from the aggregate consumption effects of cross-border shopping. Furthermore, it seems plausible that the price responsiveness of cross-border shopping is even more heterogeneous than that of domestic demand. Cross-border shopping often entails significant transportation costs and how these costs affect individual demand is likely to be highly diverse. ${ }^{2}$

We argue that our study can contribute to this literature in two ways. First, results on the effects of cross-border shopping on the externalities most commonly related to alcohol will help us to understand the full welfare implications that follow from large cross-border differences in alcohol taxes. After all, it is precisely the extent of these externalities that the governments should assess when deciding whether to respond to lower alcohol taxes in neighbouring countries by cutting taxes. Furthermore, we believe that focusing on the effects of national alcohol taxes across the border provides a novel way of evaluating the effects of alcohol policies on health and productivity outcomes. By analysing the effects of the Finnish tax cut in Sweden we can use the Swedish regions near the Finnish alcohol outlets as a treatment group and areas further away from these outlets as a control group. In this way, we can use a differences-in-differences identification strategy to identify the effects of the Finnish tax cut. This strategy would not be available if we used Finnish outcomes as outcome variables.

\section{Data}

The data used in our analysis are collected from several different sources. First, to study the impact of the reform on demand for alcohol, we obtained outlet level sales data from the state monopolies controlling the retail alcohol sales in Finland and Sweden. The data used in the analysis of the health effects of the Finnish tax cut were constructed by combining several different registers covering years 2000-2007 to the Swedish population database Louise that also contains a wide range of background characteristics for individuals. The mortality data were obtained from the death registers

\footnotetext{
${ }^{2}$ Indeed, DeCicca et al. (2010) show that, in the case of cigarettes, the socioeconomic factors affect cross-border shopping differently from typical cigarette demand models. For example, cross-border shopping of cigarettes is positively correlated with income and education level, which is not the case with regular cigarette demand.
} 
and the inpatient registers were used to define alcohol related hospital spells. Information on work absenteeisms was merged from the sickness absence registers. To fully utilise the individual variation in travelling costs, we linked the individual living locations based on Statistics Sweden's small area units from the co-ordinate database to the analysis data.

The data on alcohol sales are obtained from Alko and Systembolaget which are the state owned monopolies in Finland and Sweden. Only the outlets of these monopolies have a licence to sell stronger alcoholic beverages for off-premises consumption. The data contain annual sales of pure alcohol in litres for all retail outlets in the Northern part the countries. The sales figures are given separately for the main product categories: beer, mild drinks (including wines) and spirits. As low alcohol content drinks can also be sold in supermarkets, data are only complete for the retail sales of mild drinks and spirits. The data cover the years 2000-2007 for North Finland and 1998-2008 for North Sweden. ${ }^{3}$

The analysis population for the study of health effects is restricted to individuals living in northern Sweden within $450 \mathrm{~km}$ from the nearest town in Finland that has an Alko store. We chose this limit because this area roughly covers the northernmost counties in Sweden and includes all the regions with reasonable driving distances to the Finnish border town of Tornio. This includes the whole Norrbotten county but rules out the sparsely populated South West part of the Västerbotten county. For each individual, the distance to the closest Finnish alcohol outlet is computed in two steps. First, we utilise the publicly available real driving distance data that gives the distance from each municipality centre to the nearest Finnish town with an Alko store. We then adjust this municipality level distance measure based on the individual distance to the border from the small area units calculated using Euclidean distance measure.

The Louise database contains annual information from different administrative registers. We use age, gender, income and municipality of residence to define different analysis populations. The main analysis population consists of individuals between 15-65 years of age. For the analysis of absenteeism, we further restrict the risk set to employed individuals. We use annual earnings over of 50,000 SEK (in 2005 value) as a proxy for employment. The main data consist of an annual average of 314,000 individuals and the employed sample includes an annual average of 206,000 individuals. Because there are large gender differences in the outcome variables, males

\footnotetext{
${ }^{3}$ Drinks with alcohol content by volume up to $4.7 \%$ weight can be sold in supermarkets in Finland and alcohol content by weight up to $3.5 \%$ in Sweden.
} 
and females are analysed separately. Other variables included in the analysis are education (5 levels), occupation (8 categories) and family type which indicates having spouse or children. Each background variable is observed at the end of previous year.

We focus on the effect of the Finnish tax cut on three outcomes: mortality, alcohol related hospitalisations, and work absenteeism. The information on these outcomes is linked to the analysis data using individual identifiers. The indicator for death in a given year is obtained from the death registers. Hospitalisation due to alcohol related illness is defined using the Inpatient Register of the National Board of Health and Welfare. The hospitalisation indicator takes value one for those who have at least one of the directly alcohol related illnesses. The National Board of Health and Welfare has defined list of alcohol related ICD-10 (International Classification of Diseases) codes. The far most common reason for hospitalisation in the data is the mental and behavioural disorders due to use of alcohol (F10). The other main ICD-10 categories are alcoholic liver disease (K70), toxic effect of alcohol (T51) and external causes where alcohol involvement is determined (Y90, Y91). Also several specific alcohol related illnesses are included in the analysis but they are less common. ${ }^{4}$ The sickness absence register includes all individuals who have claimed sick leave benefits. The employers cover short sickness absence spells and the length of this spell varied from 2 to 3 weeks in the analysis period. To obtain a uniformly defined outcome, we use the definition of at least one spell of over 21 days.

\section{Alcohol sales}

In order to illustrate the effect of the Finnish tax cut on alcohol sales in northern Sweden and Finland, we obtained data on alcohol sales in the northern outlets of Systembolaget and Alko. These are the only outlets that have a right to legally sell stronger alcoholic beverages for off-premises consumption. Furthermore, decisions on the openings and closings of outlets are controlled centrally. We therefore have the full data of alcohol sales other than regular beer in both Finland and Sweden.

Figure 1 shows the map of northern Sweden covering roughly municipalities in the counties of Norrbotten and Västerbotten. Basically every Swedish municipality has at least one Systembolaget store. The dots represent the

\footnotetext{
${ }^{4}$ List of specific ICD-10 codes included in analysis: Degeneration of nervous system due to alcohol (G312), Alcoholic polyneuropathy (G621), Alcoholic cardiomyopathy (I426), Alcoholic gastritis (K292), Alcohol-induced chronic pancreatitis (K860).
} 


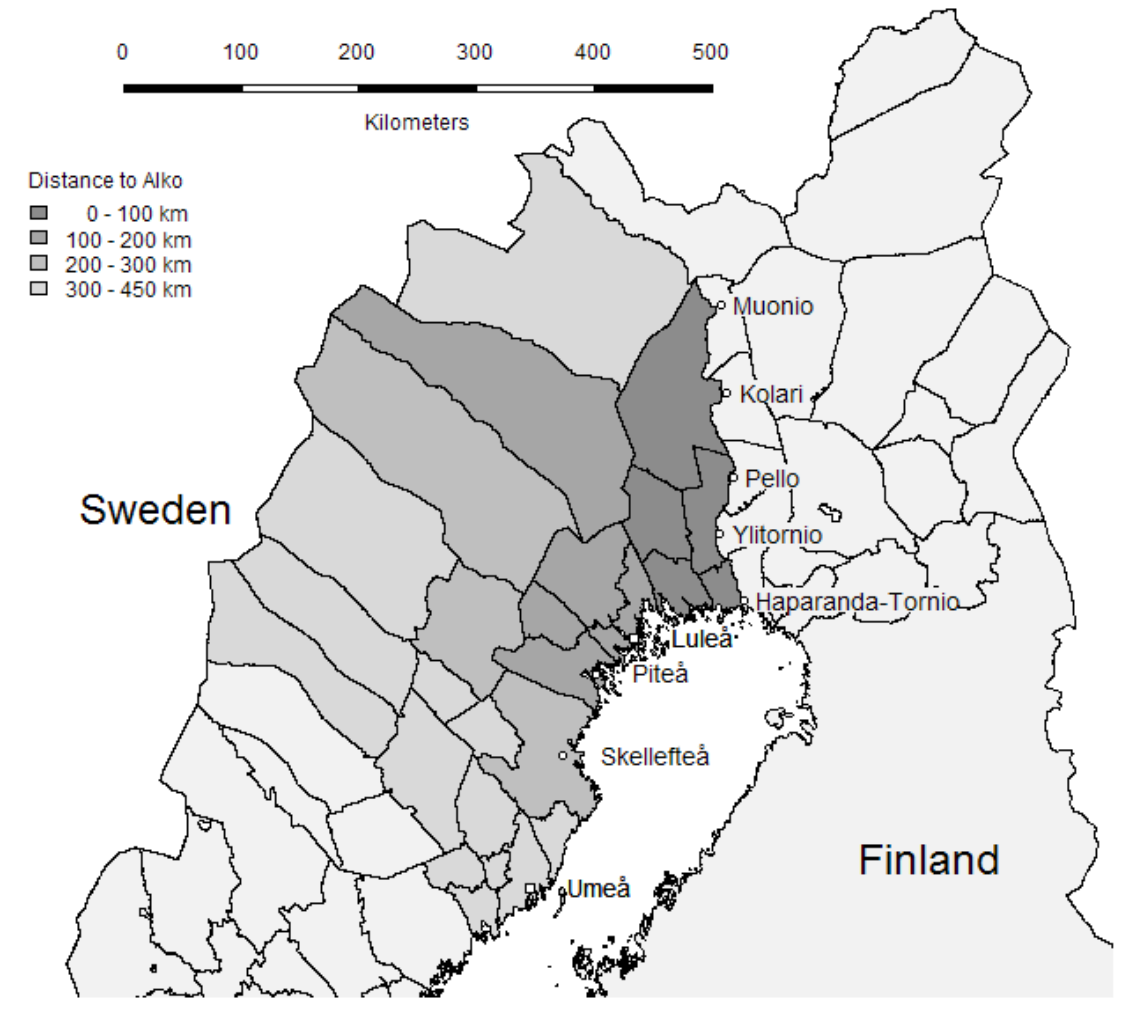

Figure 1: Map of Norrbotten and Västerbotten counties. Gray shading indicates the distance from the municipality centre to the nearest Alko outlet. 

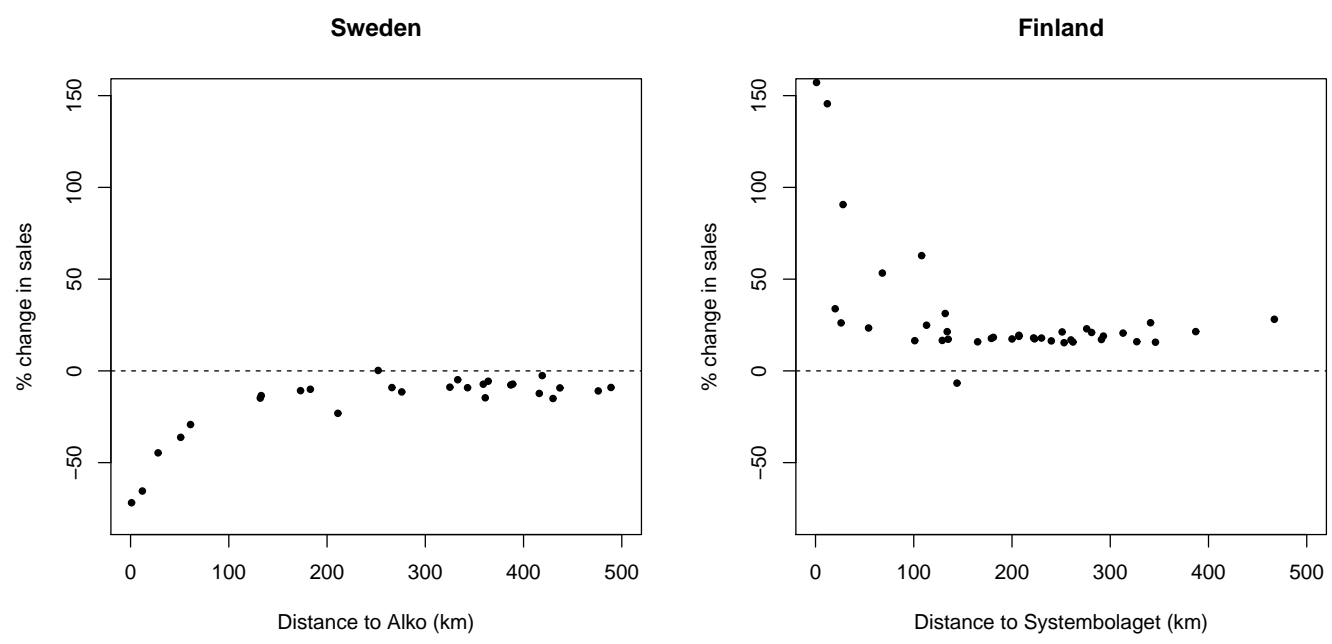

Figure 2: Change in sales of spirits between 2003 and 2004 in North Finland and northern Sweden.

four largest cities of the region on the Baltic Sea coast, and the centres of five Finnish municipalities with Alko outlet by the border between Finland and Sweden. To illustrate the driving distance from the different regions, the grey shades denote distance from each municipality centre to the nearest Alko outlet. The lightest shading denotes $0-100 \mathrm{~km}$ category and the darkest 300-400 km category. As is clear, from Figure 1, the Finnish Alko stores are located right at the Swedish border so a part of our analysis population lives very close to the Finnish outlets.

Figure 2 plots the percentage change in the sales of spirits (in litres of absolute alcohol) in both Swedish and Finnish alcohol outlets as a function of driving distance to the nearest alcohol outlet across the border between 2003-2004. As is clear from the figure, the Finnish tax cut led to dramatic changes in the sales of spirits at both sides of the border. Although the sales of spirits increased throughout Finland, the growth was much more dramatic within $100 \mathrm{~km}$ of the Swedish border. In the Alko of Tornio, the town closest to the border, sales increased well over $150 \%$ whereas further away from the border the growth was only around 20\%. Similarly Swedish sales dropped dramatically near the border with drops of around $80 \%$ in Haparanda right at the Finnish border.

We interpret Figure 2 as evidence of a substantial increase in cross-border shopping of Swedes in Finnish alcohol outlets as a result of the Finnish tax 


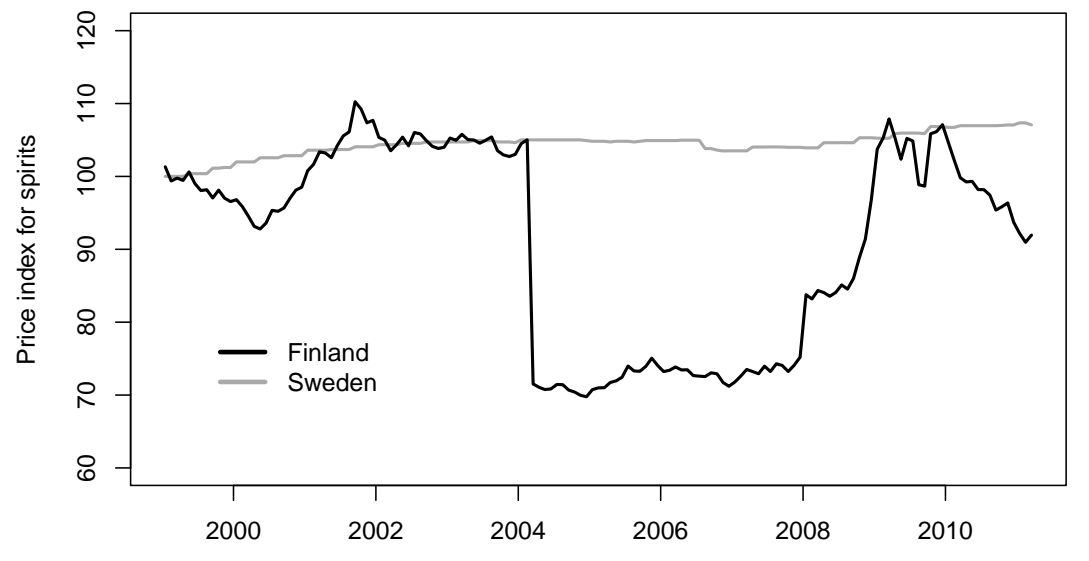

Figure 3: Prices of spirits in Finland and Sweden 1999-2011 (Swedish price in $1999=100$ ).

cut. The fact that the alcohol sales increased more in the Finnish outlets close to the Swedish border than in the rest of northern Finland combined with the fact that sales decreased most in the Swedish municipalities that are close to the Finnish border, suggests that Swedes took advantage of the increased price differences in alcohol across these two countries. These changes can be translated into litres of pure alcohol as well. Whereas the excess decline in the sales in the Swedish border regions corresponds approximately to 1605 litres of pure alcohol the corresponding excess increase in the Finnish border region is 9923 litres. Hence, if we assume that all the excess increase in sales in the Finnish border regions was due to Swedish cross-border shopping, then the amount of pure alcohol consumed in the Swedish border regions increased by 8313 litres. This amounts to an approximate increase of 0.32 litres of pure alcohol per capita in the border region.

That the sales reacted so strongly is actually not that surprising given the comparisons of prices of alcohol between Finland and Sweden. Figure 3 plots the price indices of spirits in Sweden and Finland taking the Swedish price in January 1999 as the reference value following Asplund et al. (2007). The variation in the Finnish price prior to March 2004 is mainly due to exchange 
rate variation. However, the tax cut of March 2004 lead to a dramatic divergence in prices. The Finnish spirit prices were 34 index points lower in Finland after the tax reduction whereas they were approximately at the same level before the tax cut.

Both Finnish and Swedish sales suggest that the relevant distance for the analysis of cross-border shopping is within $100 \mathrm{~km}$ of the border. In the analysis that follows we will therefore use the $100 \mathrm{~km}$ limit as a way of grouping the Swedish regions to control and treatment groups. Since this definition of the border region is admittedly somewhat ambiguous we will also present results from specifications where we control for the distance to the Finnish alcohol outlets in a more flexible way.

\section{Descriptive statistics}

Northern Sweden is a relatively sparsely inhabited area where most of the population is clustered in a small number of cities. The regional distribution of the population is important for the purposes of this study as it determines the travelling distances to the Finnish border. For most people in our data the shortest way to Finland is to drive on the European route E4 which runs on the coast of Baltic Sea and passes by the main cities in the region. Figure 4 illustrates how the 2004 analysis population is distributed in terms of distance to the Finnish border. Within $100 \mathrm{~km}$ from the border, there are several small municipalities with around 26,000 inhabitants between 15 and 65 years of age. The region between 100 and $200 \mathrm{~km}$ is more densely populated and includes larger cities such as Luleå and Piteå. Further away at $250 \mathrm{~km}$ is the city of Skellefteå and the largest city in our data is Umeå, at $390 \mathrm{~km}$ from the Finnish border.

As is common in micro-level studies of mortality and severe illnesses, all the outcomes that we study are quite rare occurrences. The average annual number of deaths is 725 in the analysis population. Hospitalisations due to alcohol related illnesses are slightly more common with around 960 cases per year. The employed workers have roughly 21,000 over three week

long sickness absence spells annually, making them a considerably more common event. Even though work absences of three weeks or more are not necessarily related to severe health problems, they are still relatively severe as an indicator of productivity.

When examining the outcome rates, they do not show any systematic increase after the tax cut in 2004 but they do reveal striking gender differences. The male mortality rates are almost twice as high as the female 


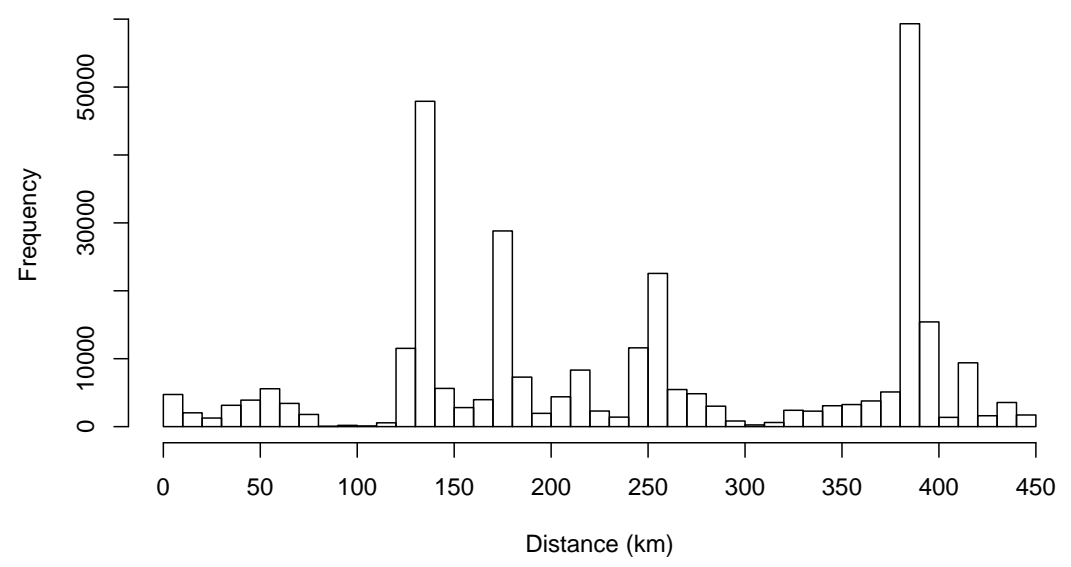

Figure 4: Individual distances to the nearest Alko outlet (2004 analysis population).

rates and the difference is even larger for alcohol related hospitalisations. The opposite is true for sickness absence as the rates for female workers are nearly double.

Table 1 describes the different analysis samples that we use in the analysis. Our main analysis is based on the comparison of people living near the border region with those living in other regions of northern parts of Sweden further away from the border. For the analysis of mortality and hospitalisations we include all individuals in the working age population in the risk set while for the analysis of sickness absence we include only those who are defined as employed. As is clear from the descriptive statistics, those living near the border are older, earn less and are less educated than those living in the rest of northern Sweden. The occupational distribution shows that employment rates are lower in the border regions and that the employed individuals are less likely to work in services. These differences are partly related to the fact that the border region does not include larger urban areas. The employed sample is slightly older, better educated and earns more as can be expected. The differences between the regions are less pronounced among employed. 
Table 1: Descriptive statistics for the border $(0-100 \mathrm{~km})$ and the other regions $(100-450 \mathrm{~km})$.

\begin{tabular}{cc|cccc} 
& & & Border & Other regions & \\
& & All & Employed & All & Employed \\
\hline \hline Age & (years) & 42.03 & 42.64 & 39.95 & 41.60 \\
Earnings & $($ 100 SEK) & 1235 & 2111 & 1532 & 2267 \\
Gender & Male & 0.531 & 0.52 & 0.514 & 0.533 \\
& Female & 0.469 & 0.48 & 0.486 & 0.467 \\
Education & Basic, lower & 0.093 & 0.04 & 0.067 & 0.043 \\
& Basic, higher & 0.167 & 0.09 & 0.137 & 0.074 \\
& High school & 0.567 & 0.64 & 0.502 & 0.553 \\
& University, lower & 0.034 & 0.039 & 0.069 & 0.062 \\
Family type & University, higher & 0.139 & 0.191 & 0.225 & 0.269 \\
& Spouse & 0.296 & 0.291 & 0.25 & 0.251 \\
& Spouse and children & 0.341 & 0.378 & 0.339 & 0.363 \\
& Single parent & 0.061 & 0.053 & 0.059 & 0.049 \\
Occupation & Single & 0.302 & 0.278 & 0.351 & 0.337 \\
& None & 0.262 & 0.011 & 0.173 & 0.009 \\
& Primary production & 0.036 & 0.031 & 0.033 & 0.034 \\
& Manufacturing & 0.125 & 0.186 & 0.124 & 0.161 \\
& Services (45-63) & 0.165 & 0.207 & 0.195 & 0.227 \\
& Services (64-75) & 0.121 & 0.162 & 0.159 & 0.191 \\
N obs & Education & 0.087 & 0.129 & 0.094 & 0.12 \\
& Health and social care & 0.16 & 0.231 & 0.175 & 0.214 \\
& Other & 0.045 & 0.043 & 0.048 & 0.044 \\
& & 160259 & 91699 & 1719360 & 1136894 \\
\hline
\end{tabular}

Note: The occupation category manufacturing includes construction. Services (45-63) refers to respective NACE codes including wholesale and retail trade, transport, hotel and restaurant services and communication. Services (64-75) includes other business services and professional activities. 


\section{$6 \quad$ Model}

The objective of this paper is to estimate how the Finnish alcohol tax cut affected Swedes living close to the Finnish border. We proceed in our analysis by dividing the data into treatment and control groups based on the $100 \mathrm{~km}$ distance limit suggested by the sales data in Figure 2. This allows us to estimate a simple differences-in-differences regression:

$$
P\left(\text { event }_{i t}\right)=\alpha+\beta X+\text { year }_{t}+\delta \text { distance }_{j}+\zeta \text { TaxCut } \cdot \text { distance }_{1},
$$

where event $t_{i t}$ is a dummy variable that takes value 1 if the outcome event takes place for individual $i$ in year $t=2000, \ldots, 2007$. $X$ is a set of observable characteristics used as control variables observed at the end of year $t-1$ and year $_{t}$ indicates year dummies. Variable distance $_{j}$ captures regional fixed effects for distance categories. These categories $j=1, \ldots, 4$ correspond to following individual distances to the Finnish alcohol outlets: 0-100, 100200, 200-300 and 300-450 km. Thus, distance 1 takes value 1 if individual lives within $100 \mathrm{~km}$ from the border. The variable TaxCut takes value 1 after year 2003, and the parameter $\zeta$ captures the effect of the Finnish tax cut.

However, the $100 \mathrm{~km}$ cut-off is a somewhat arbitrary way to group distances to the Finnish border. It is more likely that the effect of the tax cut diminishes continuously with the distance to the border. To explore this, we extend the model by using a more flexible function for distance which also allows us to exploit the individual distance variation fully:

$P\left(\right.$ event $\left._{i t}\right)=\eta+\theta X+$ Vyear $_{t}+g(\kappa \cdot$ distance $)+g(\lambda \cdot$ distance $) \cdot$ TaxCut.

Our objective is to choose a flexible but parsimonious specification for the function $g(\cdot)$. We use a third level polynomial as our preferred specification:

$$
g(\lambda \cdot \text { distance })=\lambda_{1} \text { distance }+\lambda_{2} \text { distance }^{2}+\lambda_{3} \text { distance }^{3} .
$$

This extended model is used as a robustness check for the differencesin-differences specification. The results from the extended model show, to what the outcomes responded differently to the Finnish tax cut as a function of the distance to the Finnish alcohol outlets. If the estimated polynomial indicates that the effect of the tax cut vanishes at around $100 \mathrm{~km}$, it gives support to our assumption that sales data are a good proxy for the changes is consumption.

In the main analysis, we focus on the differences-in-differences specification for the ease of interpretation. We estimate the model separately for 
Table 2: Effect of the reform in the border region.

\begin{tabular}{c|cccc} 
& Change & Estimate (S.E.) & Change & Estimate (S.E.) \\
\hline \hline Males & & & & \\
Mortality & 0.040 & $0.000165(0.000395)$ & 0.038 & $0.000158(0.000394)$ \\
Hospitalisation & -0.019 & $-0.000113(0.000489)$ & -0.004 & $-0.000026(0.000487)$ \\
Sickness absence & 0.082 & $0.005112(0.002134)$ & 0.053 & $0.003368(0.002122)$ \\
& & & & \\
Females & & & & \\
Mortality & 0.033 & $0.000066(0.000299)$ & 0.039 & $0.000079(0.000298)$ \\
Hospitalisation & -0.017 & $-0.000035(0.000303)$ & 0.020 & $0.000041(0.000303)$ \\
Sickness absence & 0.138 & $0.015895(0.002898)$ & 0.125 & $0.014481(0.002887)$ \\
& & & & \\
Controls & No & & Yes & \\
\hline
\end{tabular}

Note: The estimated standard errors (S.E.) are robust to heteroscedasticity. Control variables include age, earnings, education, family type and occupation.

males and females and we also estimate the model for various subgroups to explore the potential heterogeneity of the reform effect. The same specification is used for the three different outcomes: mortality, hospitalisation due to alcohol related illness, and sickness absence spell lasting over three weeks. We estimate the linear probability models using OLS with heteroscedasticity robust standard errors.

\section{Results}

We begin by presenting the results from the differences-in-differences model where we estimate the effect of the tax cut by comparing those living near the border with those living over $100 \mathrm{~km}$ away from the border. The estimates in Table 2 show the effect of the alcohol tax cut on the level of the outcomes rates for those near the border. To ease the interpretation we also computed the relative changes in the rates by comparing the estimated effect on the level with the predicted level of the rates in absence of the tax cut near the border in 2004. These implied changes are reported in the first column of Table 2.

As is clear from Table 2, the estimated effects vary in both sign and significance depending on the outcome. For the more severe and rare outcomes of mortality and alcohol related hospitalisation we get small and very 
imprecise estimates. For sickness absence our estimates show strong and significant increase for females while the effect is smaller for males. Controlling background characteristics changes the estimates slightly but does not change the overall picture.

The point estimates for both female and male mortality rate suggest around $4 \%$ increase in the border region after the tax cut while the point estimate for hospitalisations is near zero. However, all these estimates are far from significant and it seems that we would need higher number of events in the treatment group to draw reliable conclusion for these outcomes. Indeed, the confidence intervals for these effects are extremely wide ranging, for example, in the case of male mortality from a reduction of $15 \%$ to an increase of $22 \%$.

The estimates for sickness absence are much more precise than for the two other outcomes and quite robust to controlling for background characteristics. When the control variables are introduced, estimates become somewhat smaller and the effect on sickness absence show $5.3 \%$ increase for males and $12.5 \%$ increase for females. We also examined short-term impact of the tax cut by limiting the reform period to years 2004-2005. The shortterm effects on sickness absence were slightly larger and significant: $8.2 \%$ and $13.8 \%$ increases for males and females, respectively. These estimates suggest that the Finnish the tax cut caused a sizable increase in the sickness absence rates among those living near the border and this effect is stronger for females.

It is very likely that the Finnish alcohol tax cut had heterogeneous effect on different demographic groups. We explore this heterogeneity by estimating the differences-in-differences model for subgroups defined by age, earnings and education. These results are presented in Table 3. We only report the sickness absence results as the results on other outcomes were very imprecise. First we divide the sample to younger and older workers but the effect of the tax cut does not vary much with age. The estimates also do not vary much by the level of education but those with university degree seem to be more affected than those with less education. When we use the median earnings in the employed sample to define those with high and low earnings, we find that the tax cut had a larger effect on those earning above median. Although the pattern of these results may seem counter-intuitive - typically one would expect low-income and less educated individuals to be more responsive to prices in their alcohol consumption - they are actually in line with the existing evidence on the patterns between cross-border shopping and education and income. DeCicca et al. (2010) find that in the United States the tendency to purchase cigarettes in a neighbouring state increases 
Table 3: Heterogeneity of the effect of the tax cut on sickness absence.

\begin{tabular}{c|cccc} 
& Males & & Females \\
\hline & Change & Estimate (S.E.) & Change & Estimate (S.E.) \\
\hline Main result & 0.053 & $0.003368(0.002122)$ & 0.125 & $0.014481(0.002887)$ \\
& & & & \\
Age $\leq 40$ & 0.055 & $0.002479(0.002768)$ & 0.109 & $0.011030(0.004344)$ \\
Age $>40$ & 0.048 & $0.003718(0.003102)$ & 0.122 & $0.015156(0.003824)$ \\
& & & & \\
Lower education & 0.066 & $0.004379(0.002431)$ & 0.129 & $0.015687(0.003541)$ \\
University education & 0.112 & $0.005204(0.004242)$ & 0.140 & $0.013803(0.004958)$ \\
& & & & \\
Earnings $\leq 220$ 000 SEK & 0.033 & $0.002299(0.003286)$ & 0.110 & $0.013860(0.003675)$ \\
Earnings $>220000$ SEK & 0.089 & $0.005144(0.002780)$ & 0.173 & $0.016586(0.004632)$ \\
\hline
\end{tabular}

Note: The estimated standard errors (S.E.) are robust to heteroscedasticity. The model includes all control variables except the variable that defines the analysed subgroup.

with education and income.

Lastly we estimated the model where we allow the effect of the tax cut to vary continuously with the distance. Again we show the results only for sickness absence in Figure 5. The results for the other outcomes are in line with the results from simpler specification but they too imprecise to be informative. The estimated polynomial effects for sickness absence show that male and female rates decrease with distance up to $100 \mathrm{~km}$ and then they remain relatively steady for those living further away from the border. This means that the tax cut increased the sickness absence rates near the border when compared with other regions. Because the estimated effect is steady after $100 \mathrm{~km}$, it indicates that the tax cut did not affect the sickness absence rates there. This is in line with our results from the sales data and gives support for using these regions as a control group in the differences-in-differences setting.

The results presented in Tables 2 and 3 suggest that Finnish tax cut did indeed have health effects in the Swedish regions near the Finnish border. This is in line with the sales data that suggest that the alcohol consumption must have increased in these parts of Sweden due to increased cross-border shopping. However, unlike the earlier before-after type studies with Finnish data, we fail to find any significant effect on alcohol-related mortality or hospitalisations. There are two potential ways of interpreting this result. First, our results are based on differences-in-differences type approach where 

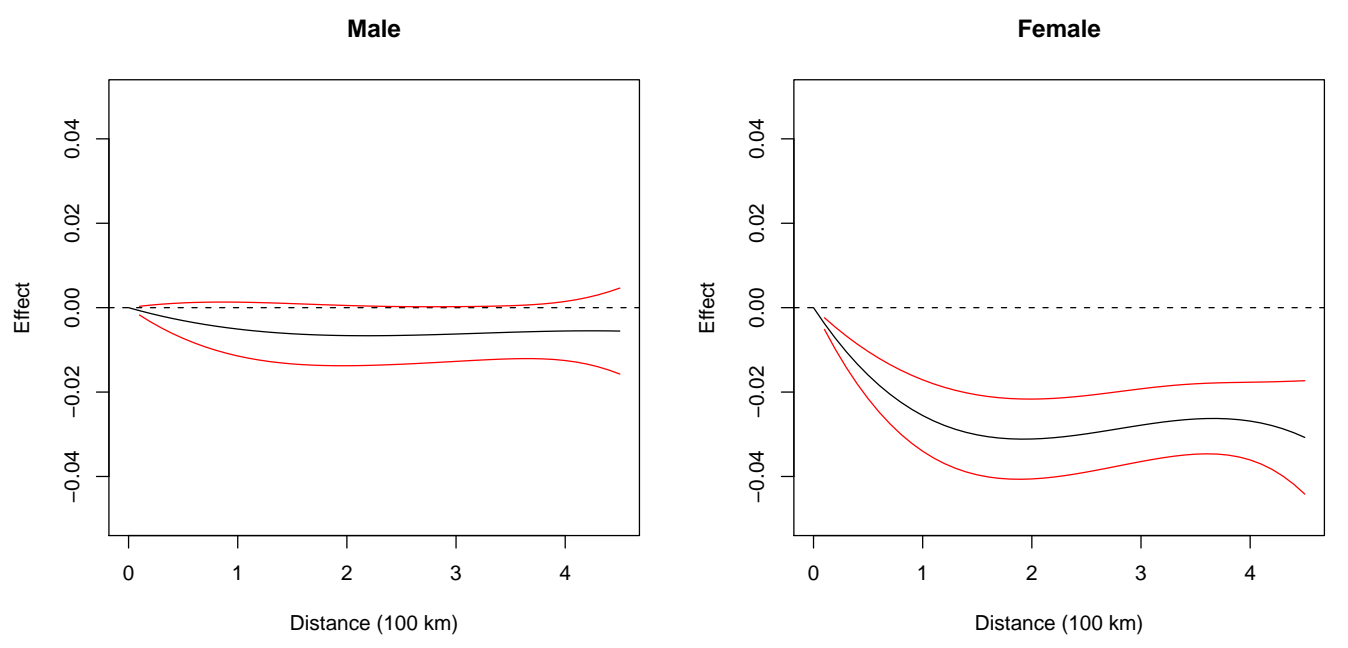

Figure 5: Effect of the tax cut in the polynomial model for sickness absence. The black lines show the estimated effect on rate as a function of distance from the border. The red lines denote $95 \%$ confidence bands.

we use regions that are further away from the Finnish border as a control group. Hence, it may be possible that the striking mortality results in the studies that use before-after comparisons may be confounding the effect of the tax cut with other changes that took place at the same time. However, it is also true that alcohol-related mortality and severe illnesses are so rare events that the sparsely populated northern Sweden simply does not provide us with enough data to analyse the effect of the tax cut on these outcomes.

However, the effects on absenteeism are more precisely estimated. To get a grasp on the magnitude of the effect of the Finnish tax cut on absenteeism in Sweden, it is useful to compare them with earlier results on the effects of alcohol policies. There are several studies that examine the relationship between alcohol consumption and sickness absenteeism. A particularly useful study for our purposes is Norström (2006) who uses Swedish time-series data to estimate the relationship between aggregate alcohol consumption and sickness absence in Sweden. According to his results, a one litre increase in total consumption of pure alcohol per capita would lead to a $13 \%$ increase in sickness absence among men. If we assume that the excess alcohol bought in the Finnish outlets near the Swedish border was all bought by working-aged Swedes in the border region, our sales results would imply an increase of approximately 0.3 litres of pure alcohol per capita. Hence, the estimated 
$5 \%$ increase in absenteeism for men is in line with the results in Norström (2006). Moreover, our results on sales and absenteeism are remarkably similar to the forecast made by Andreasson et al. (2006) who estimate that

reducing taxes in Sweden to post-2004 Finnish levels would increase alcohol consumption by 0.35 litres per capita and increase sickness absenteeism by 3-5\%. Yet, compared to the time-series variation in the Swedish sickness absence rates, the changes implied by our results are small. For example, in the early 1990's sickness absence rates halved from the very high levels in the late 1980's. Previous literature, such as Johansson \& Palme (1996), has shown that sickness absence is very sensitive to changes in replacement rates. Compared to the effects of such policies, the effects of cross-border shopping to due to changes in alcohol policies are not large.

\section{Conclusions}

There has been an intense debate on the implications of cross-border shopping for the efficiency of national excise taxes in recent years. While most of this debate has concentrated on the revenue impacts of cross-border shopping, we argue that in order to get a complete understanding of the welfare implications of cross-border shopping, one has to know the externalities that are caused by cross-border shopping. In the case of alcohol, this requires the direct estimation of cross-border externalities. In this paper, we estimate the effect of a large cut in Finnish alcohol taxes on health outcomes in Sweden.

On March 1st, 2004 Finland implemented a tax cut that led to an average $19 \%$ decrease in the retail prices of all alcoholic beverages and to an average cut of $36 \%$ in the price of spirits. We focus on the health and productivity effects of this tax cut in the Swedish regions that are adjacent to the Finnish border. The Finnish and Swedish border regions are a promising setting for analysing the cross-border health and productivity effects of national alcohol policies since the sale of alcohol is constrained to state owned monopoly. At the same time, however, there are no restrictions on cross-border shopping.

Our analysis shows that Swedes clearly took advantage of the increased price difference between the countries. Our results on the effect of the Finnish tax cut on mortality or alcohol hospitalisations in Sweden are very imprecise, which is in sharp contrast to the results in papers that find large health effects of excise taxes within national borders. The failure to find such effects in Northern Sweden is probably due to the fact that the treatment region is too sparsely populated to allow one to catch effects on such 
rare occurrences such as mortality due to alcohol. On the other hand, we do find significant effects on absenteeism in northern Sweden. The tax cut lead to increased workplace absenteeism in the Swedish regions near the Finnish border by $5 \%$ for males and by $13 \%$ for females when compared to those over $100 \mathrm{~km}$ away from the border. These results are in line with the earlier studies on the relationship between sickness absence and alcohol consumption. Hence, the increased consumption in Sweden due to the Finnish tax cut did have negative externalities in the form of productivity effects.

\section{References}

Andreasson, S., Holder, H., Norström, T., Österberg, E. \& Rossow, I. (2006), 'Estimates of harm associated with changes in swedish alcohol policy: results from past and present estimates', Addiction 101(8), 1096-1105.

Asplund, M., Friberg, R. \& Wilander, F. (2007), 'Demand and distance: evidence on cross-border shopping', Journal of public Economics 91(12), 141-157.

Ayyagari, P., Deb, P., Fletcher, J., Gallo, B. \& Sindelar, J. (2009), 'Sin Taxes: Do Heterogeneous Responses Undercut Their Value?', NBER Working Paper .

Chesson, H., Harrison, P. \& Kassler, W. (2000), 'Sex under the influence: The effect of alcohol policy on sexually transmitted disease rates in the United States', Journal of Law and Economics 43(1), 215-238.

Cnossen, S. (2007), 'Alcohol taxation and regulation in the European Union', International Tax and Public Finance 14(6), 699-732.

DeCicca, P., Kenkel, D. \& Liu, F. (2010), 'Excise Tax Avoidance: The Case of State Cigarette Taxes', NBER Working Paper.

Grossman, M. (1993), The economic analysis of addictive behavior, in 'Economics and the prevention of alcohol-related problems', National Institute on Alcohol Abuse and Alcoholism, Bethesda, MD, pp. 91-123.

Herttua, K., Makela, P. \& Martikainen, P. (2008), 'Changes in alcoholrelated mortality and its socioeconomic differences after a large reduction in alcohol prices: a natural experiment based on register data', American journal of epidemiology 168(10), 1110-1118. 
Johansson, P. \& Palme, M. (1996), 'Do economic incentives affect work absence? empirical evidence using swedish micro data', Journal of Public Economics 59(2), 195-218.

Koski, A., Siren, R., Vuori, E. \& Poikolainen, K. (2007), 'Alcohol Tax Cuts and Increase in Alcohol-Positive Sudden Deaths - A Time-Series Intervention Analysis', Addiction 102, 362-368.

Lankinen, H. (2005), 'Alkoholiveron alennuksen hintavaikutuksista', Kansantaloudellinen aikakauskirja 101(1), 81-83.

Manning, W., Blumberg, L. \& Moulton, L. (1995), 'The demand for alcohol: The differential response to price', Journal of Health Economics 14(2), 123-148.

Merriman, D. (2010), 'The micro-geography of tax avoidance: evidence from littered cigarette packs in Chicago', American Economic Journal: Economic Policy 2(2), 61-84.

Norström, T. (2006), 'Per capita alcohol consumption and sickness absence', Addiction 101(10), 1421-1427.

Ohsfeldt, R. \& Morrisey, M. (1997), 'Beer taxes, workers' compensation, and industrial injury', Review of Economics and Statistics 79(1), 155-160.

Sloan, F., Reilly, B. \& Schenzler, C. (1994), 'Effects of prices, civil and criminal sanctions, and law enforcement on alcohol-related mortality.', Journal of studies on alcohol 55(4), 454.

Wagenaar, A., Salois, M. \& Komro, K. (2009), 'Effects of beverage alcohol price and tax levels on drinking: a meta-analysis of 1003 estimates from 112 studies', Addiction 104(2), 179-190. 